\title{
The Synthesis of Carbon Nanomaterials using Chlorinated Hydrocarbons over a Fe-Co/ $\mathrm{CaCO}_{3}$ Catalyst
}

\author{
Winny K. Maboya ${ }^{a, b}$, Neil J. Coville ${ }^{b}$ and Sabelo D. Mhlanga ${ }^{b, c, *}$ \\ ${ }^{a}$ Department of Chemistry, Faculty of Applied and Computer Sciences, Vaal University of Technology, \\ Private Bag X021, Vanderbijlpark, 1900, South Africa. \\ ${ }^{b}$ DST-NRF Centre of Excellence in Strong Materials and Molecular Sciences Institute, School of Chemistry, \\ University of the Witwatersrand, Johannesburg, WITS, 2050, South Africa. \\ ${ }^{c}$ Nanotechnology and Water Sustainability Research Unit, College of Science, Engineering and Technology, \\ University of South Africa, Florida Science Campus, Johannesburg, 1709, South Africa.
}

Recieved 6 July 2015, revised 8 December 2015, accepted 10 December 2015

Dedicated to Professor Cedric Holzapfel on the occasion of his 80th birthday.

\begin{abstract}
The effect of chlorine on the morphology of carbon nanotubes (CNTs) prepared from a $\mathrm{Fe}-\mathrm{Co} / \mathrm{CaCO}{ }_{3}$ catalyst was investigated using chlorobenzene (CB), dichlorobenzene (DCB), trichlorobenzene (TCB), dichloroethane (DCE), trichloroethane (TCE) and tetrachloroethane (TTCE) as chlorine sources using a catalytic chemical vapour deposition (CCVD) method. Toluene was used as a chlorine-free carbon source for comparison. Multi-walled carbon nanotubes (MWCNTs) were successfully synthesized. The physicochemical properties of the CNTs were studied using transmission electron microscopy (TEM), Raman spectroscopy, thermal gravimetric analysis (TGA), energy-dispersive X-ray spectroscopy (EDS), powder X-ray diffraction (PXRD) spectroscopy, and X-ray photoelectron spectroscopy (XPS) techniques. The inner and outer diameters of the MWCNTs increased with an increase in the number of chlorine atoms contained in the reactant. Chlorine incorporation into the MWCNTs was observed by EDS analysis for all reactants. Formation of 'bamboo-like' structures for the MWCNTs generated from TCE and TTCE was also observed, facilitated by the presence of the high percentage of chlorine in these reactants. Numerous MWCNTs revealed the presence of small carbon nanostructures that grew on top of the dominant CNTs, suggesting an unexpected secondary carbon growth mechanism.
\end{abstract}

KEYWORDS

Multi-walled carbon nanotubes, CVD, synthesis, chlorine, benzenes, ethanes.

\section{Introduction}

Nanotechnology is a topic that is attracting the interest of scientists in academia, research institutions and industry as well as government officials and journalists. Carbon nanotubes (CNTs) and carbon nanomaterials (CNMs) in general are key components in the progress of nanotechnology. Polyhedral carbon clusters (fullerenes) were discovered in $1985^{1}$ and this eventually led to the seminal studies on carbon nanotubes (CNTs) by Ijima in $1991 .{ }^{2}$ CNTs offer opportunities for the development of novel material systems because they possess unique electronic properties, ${ }^{3}$ exhibit thermal conductivity that is higher than that of diamond, ${ }^{3}$ and possess mechanical properties such as stiffness, strength and resilience, which exceed those of any currently used materials. ${ }^{4}$ These unique properties render CNTs suitable for application in various fields for example, their use as supports in catalysis, nanoconveyors, field emission sources, chemical sensors, nanoelectronic devices and in fuel cells., ${ }^{5}$ Methods for making CNTs such as arc discharge, laser ablation, pyrolysis and catalytic chemical vapour deposition (CCVD) have been developed. ${ }^{7-10}$ To date the production of CNTs by the CCVD method remains the preferred route for their large scale production.

A limitation related to the use of CNTs in many applications has always been the difficulty in dispersing them in solvents.

* To whom correspondence should be addressed. E-mail: mhlansd@ unisa.ac.za
Scientists have thus functionalized the outer walls of CNTs with various groups like halogens and carboxylic groups to improve their solubility. Modification of CNTs has thus led to the creation of new functional and construction materials. ${ }^{11}$ Doping of the carbonaceous materials with non-carbon atoms, such as nitrogen, ${ }^{12-19}$ boron, ${ }^{20-24}$ sulphur, ${ }^{25-29}$ oxygen ${ }^{30-36}$ and halogen $s^{11,37-55}$ has been explored over the past two decades. Modification of the carbon surface and electronic properties has also been explored but the effect of chlorine $(\mathrm{Cl})$ on the morphology of carbon nanomaterials is not well established.

It has been shown that incorporation of $\mathrm{Cl}$ in the $\mathrm{CNMs}$ results in surface functionalization, ${ }^{41-44}$ ease of purification, ${ }^{40,43,45,46}$ increased yields ${ }^{47-49}$ and surface restructuring. ${ }^{49,50}$ The presence of chlorine atoms thus produces materials with increased inner diameters, which results in filling of CNTs with metal particles ${ }^{51-53}$ and provides a chemically modified pathway to an ordered carbon product. ${ }^{48,49,54}$ Liquid chlorination of multi-walled CNTs (MWCNTs) gave a $\mathrm{Cl}$ loading of about 0.23 at. $\%{ }^{40}$ based on EDS. XPS analysis of single-walled carbon nanotubes produced from dichlorocarbene gave $\mathrm{Cl}$ substituted $\mathrm{CNTs}$ at a concentration of 1.6 at. \%. ${ }^{41} \mathrm{~A}$ small number of $\mathrm{Cl}$ anions were also observed on the surface of the CNTs generated from dichloromethane by XPS analysis. ${ }^{11}$ Chlorine-functionalized CNTs were also produced in the gas phase using a ball-milling method. ${ }^{42}$ Purification of CNTs with $\mathrm{Cl}$ in both the liquid phase (using $\mathrm{CCl}_{4}$ ) and the gas phase to 
remove metal particles showed that the gas phase was more effective, but a high concentration of $\mathrm{Cl}$ on the surface was loaded in the liquid phase. ${ }^{43}$ Purification and growth of vertically aligned MWCNTs in the presence of $\mathrm{Cl}$ was also reported, which resulted in the synthesis of CNT arrays with $3.5 \mathrm{~mm}$ height. ${ }^{44}$

The yield of MWCNTs increased from $10 \%$ to over $50 \%$ using an arc discharge method and $\mathrm{KCl}$ as a promoter. ${ }^{47} \mathrm{CNMs}$ produced from chlorobenzene were more ordered and their yield increased as compared to those obtained from benzene. ${ }^{48}$ The beneficial role of halogens involving charge transfer with $\mathrm{Ni}$ particles has been shown by other authors. ${ }^{48,49}$ An interaction between $\mathrm{Cl}$ and $\mathrm{Ni}$ leading to metal site restructuring was observed when carbon nanofibres (CNFs) were grown from $\mathrm{Ni} / \mathrm{SiO}_{2}$ and chlorobenzene. ${ }^{50}$ When the $\mathrm{CNMs}$ were grown over $\mathrm{Ni} / \mathrm{SiO}_{2}$ carbon yields were also shown to increase in the presence of $\mathrm{Cl}$, in the order $\mathrm{C}_{2} \mathrm{H}_{6}<\mathrm{C}_{2} \mathrm{H}_{4}<\mathrm{C}_{2} \mathrm{H}_{4} \mathrm{Cl}_{2}<\mathrm{C}_{2} \mathrm{H}_{3} \mathrm{Cl}_{3}<$ $\mathrm{C}_{2} \mathrm{H}_{2} \mathrm{Cl}_{2} \leq \mathrm{C}_{2} \mathrm{HCl}_{3}$. The fibre diameter increased with increased $\mathrm{Cl}$ substitution in the feed. ${ }^{49}$ Structural changes to give carbons with different structure (CNFs to carbon spheres) were observed when $\mathrm{CCl}_{2}=\mathrm{CHCl}$ was used as a chlorine feed. ${ }^{49} \mathrm{CNFs}$ with tripod-like morphology were also synthesized over a $\mathrm{NiO}$ xerogel catalyst using trichloroethylene as $\mathrm{Cl}$ feed and carbon source. ${ }^{54}$ Synthesis of CNTs over a Fe-Ni catalyst was achieved using chlorinated benzenes and it was observed that the hollow degree of the CNTs increased with an increase in $\mathrm{Cl}$ content in the feed, which resulted in the CNTs being filled with a Fe-Ni alloy. ${ }^{51}$ Previous work in our group has also shown that the use of chlorobenzene can facilitate growth of CNTs with a large inner cavity. ${ }^{53}$ The participation of $\mathrm{Cl}$ was found to play an important role in the synthesis of turbostratic CNFs by pyrolysis of a 1,2-dichloroethane/ethanol mixture in the presence of a nickel catalyst. ${ }^{55}$ $\mathrm{Ni}-\mathrm{Cl}$ bonding on the surface of the catalyst created a poor crystalline layer, leading to a coarse surface which caused the disordered precipitation of carbon species and thus the formation of turbostratic CNFs. ${ }^{55}$ Most of the studies of the role of chlorine on the morphology of the CNMs have been investigated using a nickel or iron-nickel catalyst.

In previous studies by our group it was found that a $\mathrm{Fe}-\mathrm{Co} / \mathrm{CaCO}_{3}$ catalyst can be used to make good quality $\mathrm{CNTs}^{56,57}$ and nitrogen doped CNTs. ${ }^{58}$ To further explore the role of this catalyst we have investigated the role of chlorine on the morphology of CNTs produced by pyrolysis of various chlorinesubstituted benzene and ethane feeds using a CCVD method. The results of the study are shown below.

\section{Experimental}

$\mathrm{Fe}\left(\mathrm{NO}_{3}\right)_{3} \cdot 9 \mathrm{H}_{2} \mathrm{O}$ (Sigma Aldrich) $\geq 98 \%, \mathrm{Co}\left(\mathrm{NO}_{3}\right)_{2} \cdot 6 \mathrm{H}_{2} \mathrm{O}$ (Sigma Aldrich) $\geq 98 \%, \mathrm{CaCO}_{3}$ (Sigma Aldrich) $\geq 99 \%, \mathrm{HNO}_{3}$ (Sigma Aldrich) $\geq 98 \%$ ACS, chlorobenzene (CB) (Merck), >99\% GC, 1,2-dichlorobenzene (DCB) (Sigma Aldrich) $99 \%$ Reagent plus, 1,2,4-trichlorobenzene (TCB) (Sigma Aldrich) $99 \%$ GC, 1,2-dichloroethane (DCE) (BDH reagent) AnalaR grade, 1,1,2-trichloroethane (TCE) (Fluka Chemika) >98\% GC, 1,1,2,2-tetrachloroethane (TTCE) (UniLAB SAARChem) $98 \%$ GLC and toluene (UniLab SAARChem, Merck) ACS reagent grade, were used. All the reagents were commercially available and used without further purification.

\subsection{Preparation of Catalyst by the Wet Impregnation Method}

The preparation of catalysts was done as reported in previous studies. ${ }^{56,57} \mathrm{Fe}\left(\mathrm{NO}_{3}\right)_{3} \cdot 9 \mathrm{H}_{2} \mathrm{O}$ and $\mathrm{Co}\left(\mathrm{NO}_{3}\right)_{2} \cdot 6 \mathrm{H}_{2} \mathrm{O}$ were used to prepare the catalyst. Calculated amounts of the $\mathrm{Fe}$ and Co nitrates were mixed, ground to a fine powder and dissolved in distilled water to make a $0.3 \mathrm{~mol} \mathrm{~L}^{-1} \mathrm{Fe}-\mathrm{Co}(50: 50 \mathrm{~m} / \mathrm{m})$ precursor solution. This solution $(30 \mathrm{~mL})$ was added to the $\mathrm{CaCO}_{3}$ support $(20 \mathrm{~g})$ and the mixture was stirred for $30 \mathrm{~min}$. The metal-support mixture was then dried in the oven at $120^{\circ} \mathrm{C}$ for $12 \mathrm{~h}$, cooled to room temperature, ground and finally screened through a $150 \mu \mathrm{m}$ sieve. The catalyst powder was then calcined at $400^{\circ} \mathrm{C}$ for $16 \mathrm{~h}$ in a static air oven. This catalyst was completely characterized as reported in our previous article. ${ }^{56}$

\subsection{Carbon Nanotube Synthesis}

The catalyst $(1.0 \mathrm{~g})$ was spread in a quartz boat and the boat was placed in the centre of the quartz tube. The furnace was then heated to $700{ }^{\circ} \mathrm{C}$ at a rate of $10^{\circ} \mathrm{C}$ min ${ }^{1}$ under flowing $\mathrm{N}_{2}(50 \mathrm{~mL}$ $\min { }^{1}$ ). Once the temperature reached $700{ }^{\circ} \mathrm{C}$, the $\mathrm{N}_{2}$ flow rate was set to $240 \mathrm{~mL} \mathrm{~min}^{-1}$ and $\mathrm{C}_{2} \mathrm{H}_{2}$ was set at $90 \mathrm{~mL} \mathrm{~min}^{1}$ for chlorinated benzenes; for chlorinated ethanes flow rates were set at $280 \mathrm{~mL} \min { }^{1} \mathrm{~N}_{2}$ and $50 \mathrm{~mL} \min { }^{1} \mathrm{C}_{2} \mathrm{H}_{2}$, respectively. Both gases were bubbled through a chlorinated organic solvent, before introduction into the quartz tube. After $60 \mathrm{~min}$ of reaction time, the $\mathrm{C}_{2} \mathrm{H}_{2}$ flow and bubbling was stopped and the system was left to cool down to room temperature under a continuous flow of $\mathrm{N}_{2}$ $\left(50 \mathrm{~mL} \mathrm{~min}^{-1}\right)$. The reaction setup is shown in Fig. 1. The quartz boat was then removed from the reactor and the carbon deposit (Cl-MWCNTs) that formed was weighed.

\subsection{Purification of the CNTs}

Purification of the CNT materials was performed as described elsewhere. ${ }^{56}$ The CNTs were purified by stirring the products in $30 \% \mathrm{HNO}_{3}$ for at least $30 \mathrm{~min}$ at room temperature. The acid-treated CNTs were then washed with distilled water until the washings were neutral and dried in an oven at $120^{\circ} \mathrm{C}$ for $12 \mathrm{~h}$.

\subsection{Characterization of the Catalyst and CNTs}

The morphology and size distribution of the CNTs before and after $\mathrm{HNO}_{3}$ treatment were analyzed by transmission electron

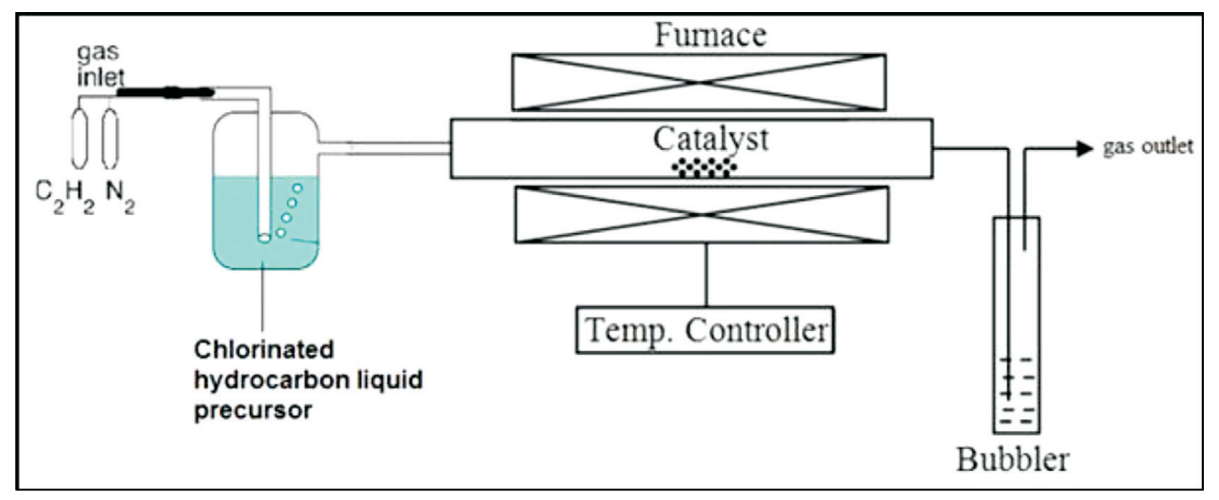

Figure 1 Schematic diagram of apparatus used for CNT synthesis. 
microscopy (TEM) using a FEI TECNAI G ${ }^{2}$ SPIRIT. The samples for TEM analysis were prepared by sonication in ethanol and thereafter deposited on a holey carbon-coated TEM Cu grid. The percentage yield of the carbon deposit (\% C) was determined as described elsewhere. ${ }^{59}$ The CNTs were also characterized by Raman spectroscopy using a Jobin-Yvon T6400 micro-Raman spectrometer. Excitation was provided by the $532 \mathrm{~nm}$ green laser with spectral resolution of $3-5 \mathrm{~cm}^{-1}$. The impurity content of the CNTs was monitored by thermogravimetric analysis (TGA) using a Perkin Elmer TGA 7. The sample was loaded onto a platinum pan and heated to $900{ }^{\circ} \mathrm{C}$ at a heating rate of $5^{\circ} \mathrm{C} \mathrm{min}{ }^{1}$, in a flowing air and nitrogen stream both at $20 \mathrm{~mL} \mathrm{~min}{ }^{1}$. The phase composition of the samples was determined by powder X-ray diffraction (PXRD) using a D2 Bruker PXRD with a continuous scan mode using $\operatorname{CoK} \alpha$ radiation. The scan range was 10-90 $2 \theta$ degree. The presence of chlorine species in the CNT samples was determined by energy dispersive X-ray spectroscopy (EDS) incorporated into the SEM. XPS analysis was performed using a PHI 5000 Versaprobe - Scanning ESCA Microprobe operating with a $100 \mu \mathrm{m} 25 \mathrm{~W} 15 \mathrm{kV}$ Al monochromatic X-ray beam. The samples were sputtered with a $2 \mathrm{kV} 2 \mu \mathrm{A}$ $1 \times 1 \mathrm{~mm}$ raster - Ar ion gun at a sputter rate of about $18 \mathrm{~nm} \mathrm{~min}^{-1}$ for 60 seconds.

\section{Results and Discussion}

The results from the studies of Mhlanga et. al. ${ }^{56}$ and Tetana et. al. ${ }^{58}$ showed that good quality MWCNTs and nitrogen doped MWCNTs can be produced from a $\mathrm{Fe}-\mathrm{Co} / \mathrm{CaCO}_{3}$ catalyst. This led us to assume that other hydrocarbons, such as chlorinated hydrocarbons, could be used to make CNTs over this catalyst. All the products made in the study were black in colour; those obtained with $\mathrm{CB}, \mathrm{DCB}, \mathrm{DCE}$, and TCE as chlorine sources appeared spongy, while those obtained with TCB, TTCE and toluene were powdery.

\subsection{Structural Analysis of the Cl-MWCNTs}

TEM analysis of the carbon deposits after acid treatment showed that the morphologies of CNMs varied with the type of feed used. A range of carbons were produced in varying amounts, i.e. amorphous material, CNFs and CNTs (open and bamboo), but CNTs were the predominant products formed in most cases.

Purified CNTs produced from CB, DCB and TCB all appeared entangled with a wavy (cooked spaghetti-like) morphology (Figs. 2, 3 and 4). It appears that all the aromatic chlorine containing reactants gave similar carbon yields (ca. 63-70\%). Purified MWCNTs produced using TCB were more entangled and their inner and outer diameters appeared uniform over the entire length of the tube (Fig. 4). The diameters of the purified CNTs produced from the three reactants are given in Table 1 . Both the inner and outer diameters increased with the reactant's chlorine content.

TEM analysis also showed the presence of rod shaped catalyst particles embedded inside the nanotubes (Figs. 2 and 4) and some at the tips of the CNFs (Fig. 3 insert), which were formed as a result of un-reacted catalyst particles. This shows that CNTs obtained from the aromatic compounds contained some metal particles which were difficult to purify and this was attributed to the coiled structures as well as their narrow inner diameters (Table 1).

Further analysis of TEM images of purified carbon materials produced from DCB revealed the presence of small open ended fibrous particles attached to the outside of the CNTs (Fig. 3 and Supplementary Fig. S1). The secondary nanofibres were initially

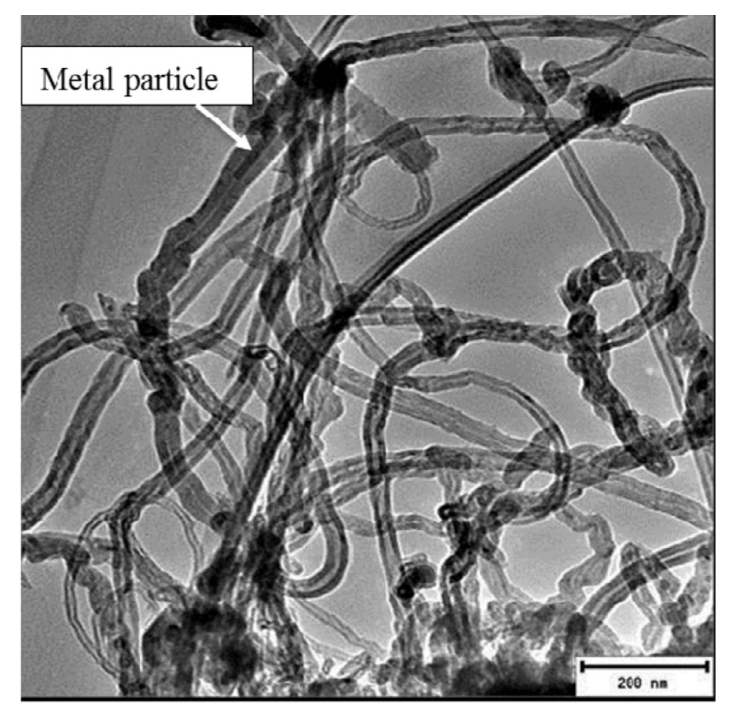

Figure 2 TEM image of the purified carbonaceous materials generated using chlorobenzene as chlorine source.

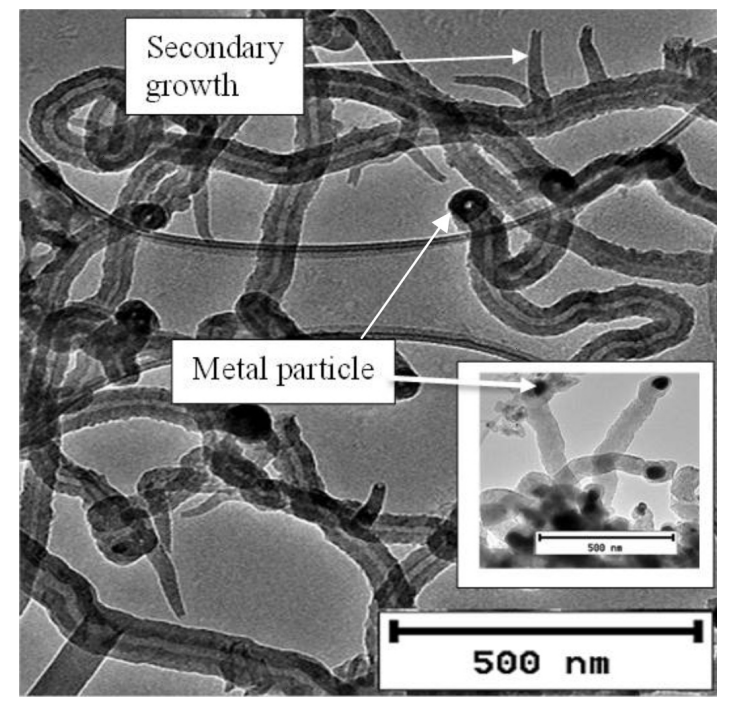

Figure 3 TEM image of the purified carbonaceous materials generated using dichlorobenzene as chlorine source. Growth of small carbon materials on the surface of the CNTs. Insert shows metal particles at tips of CNFs.

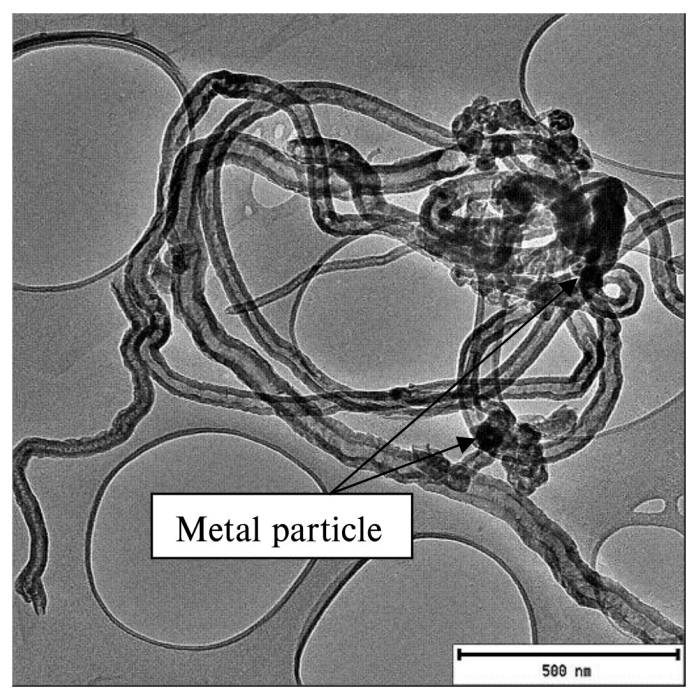

Figure 4 TEM images of the purified carbonaceous materials generated using trichlorobenzene. 
Table 1 Effect of the reactants on the structure, outer and inner diameters of the purified MWCNTs.

\begin{tabular}{|c|c|c|c|c|c|}
\hline Chlorine source & $\begin{array}{l}\text { Outer diameter } \\
\text { size distribution } \\
\qquad / \mathrm{nm}\end{array}$ & $\begin{array}{l}\text { Average outer } \\
\text { diameter } \\
/ \mathrm{nm}\end{array}$ & $\begin{array}{l}\text { Inner diameter } \\
\qquad / \mathrm{nm}\end{array}$ & $\begin{array}{l}\text { Predominant carbon } \\
\text { structure }\end{array}$ & $\begin{array}{c}\text { Volume of hydrocarbon } \\
\text { source used } \\
/ \mathrm{mL}\end{array}$ \\
\hline СВ & $11-44$ & 29 & $3-9$ & $\begin{array}{c}\text { CNTs and a measurable } \\
\text { quantity of } \\
\text { 'Bamboo-like' CNTs }\end{array}$ & 0 \\
\hline DCB & $\begin{array}{c}22-41 \text { (CNTs) } \\
62-100 \text { (CNFs) }\end{array}$ & $\begin{array}{l}33 \\
77\end{array}$ & $6-11$ & CNTs & 0 \\
\hline TCB & $23-79$ & 49 & $17-21$ & CNTs & 0 \\
\hline Toluene & $7-79$ & 29 & 3 & CNTs & 5 \\
\hline DCE & $\begin{array}{c}52-166 \text { (CNFs) } \\
10-30 \text { (CNTs) }\end{array}$ & $\begin{array}{r}108 \\
15\end{array}$ & 4 & CNFs & 5 \\
\hline TCE & $16-23$ & 20 & 5 & $\begin{array}{l}\text { CNTs and measurable } \\
\text { 'Bamboo-like' CNTs }\end{array}$ & 2 \\
\hline TTCE & $29-66$ & 50 & 12 & $\begin{array}{l}\text { CNTs and measurable } \\
\text { 'Bamboo-like' CNTs }\end{array}$ & 1 \\
\hline
\end{tabular}

broad and then became narrower as they grew from the primary CNTs. Close inspection of the numerous CNFs produced revealed that they all have an inverted cap-like morphology suggesting a loss of metal catalyst particles at the tip. The secondary growth was thought to originate from unreacted catalyst particles that were left on the surface of the CNTs grown via a tip-growth mechanism. The catalyst responsible for the secondary growth was presumably trapped on the surface of the growing CNTs and provided a growth site for secondary CNTs. Similar behaviour was reported in the literature where some particles were found attached to the ends of CNTs. ${ }^{60}$

A small carbon deposit was obtained when TCB was used as chlorine source (Fig. 4). The large amount of chlorine in the TCB feed was responsible for the few CNTs measured, which was attributed to $\mathrm{Cl} / \mathrm{Fe}-\mathrm{Co}$ interactions leading to metal site restructuring that impacted on carbon diffusion/precipitation. ${ }^{50}$ The various morphologies that resulted from the different chlorinated feeds were possibly associated with the interaction of chlorine with the catalyst particles. As more chlorine was introduced into the reactor the rate of $\mathrm{CNT}$ formation decreased, due to catalyst poisoning.

Toluene as a representative of a $\mathrm{Cl}$ free aromatic hydrocarbon was also tested in this study (Fig. 5). Toluene produced irregular CNTs of similar inner $(3 \mathrm{~nm})$ and variable outer diameters (7-79 $\mathrm{nm})$. MWCNTs of variable inner (7-14 nm) and outer (22-64 nm) diameters were produced from a mixture of toluene and ferrocene; iron oxide particles were also seen embedded inside some on the outer walls of the CNTs. ${ }^{61}$ In another study mixed quality carbon structures (irregular tubes of different diameters, rods, spirals, fibres, etc.) were found by electron microscopy when toluene was used as a hydrocarbon source over an Fe/silica substrate. ${ }^{62}$ Metal particles can also be seen embedded inside some of the CNTs produced in this study (Fig. 5). Comparison of the CNTs produced using chlorinated benzenes with those obtained using toluene shows that the presence of chlorine in the aromatic feed leads to more regular CNTs.

TEM images of the purified MWCNTs produced from the three chlorinated ethanes all appeared entangled with a coiled spaghetti-like shape (Figs. 6, 7 and 8). The purified CNMs produced from DCE contained a mixture of mainly CNFs (Fig. 6a) and some CNTs (Fig. 6b). CNTs with little by-product formation were obtained from TCE and TTCE (Figs. 7 and 8). The formation of CNFs must relate to the amount of hydrogen present in the DCE $\left(\mathrm{C}_{2} \mathrm{H}_{4} \mathrm{Cl}_{2}\right)$ feed. ${ }^{63}$

The carbon yields obtained using chlorinated ethanes were 92, 82 and $81 \%$ for DCE, TCE and TTCE, respectively. The carbon yields were not dependant on the amount of chlorine present in the feed. The TEM images of carbon materials produced from TCE are shown in Fig. 7. The three figures reveal different features associated with the CNTs. Fig. 7a highlights the entangled CNTs and many of these CNTs appear to show bamboo compartment features. Fig. $7 \mathrm{~b}$ shows secondary growth of short CNTs with hollow tips, which seem to originate from the main CNTs. These are similar to those seen above in Fig. 3 when DCB was used as a reactant, but here tubes do not taper and the hollow structures can be clearly seen. Finally wine glass-like secondary structures were also seen in Fig. 7c. These secondary structures had very thin walls and did not show the presence of catalyst particles. The presence of un-reacted catalyst material on the surface of the CNTs could be responsible for the secondary growth via a tip-growth mechanism.

MWCNTs produced using TTCE also appeared entangled with different outer wall diameters (Fig. 8a, b). Numerous small particles can also be observed on the surface of the CNTs, but no

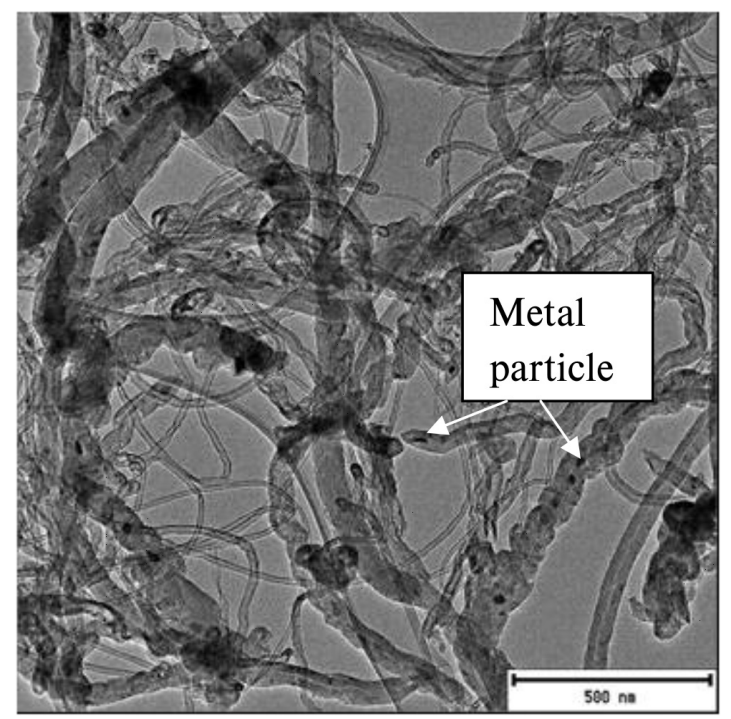

Figure 5 TEM images of the purified carbonaceous materials generated using toluene. 

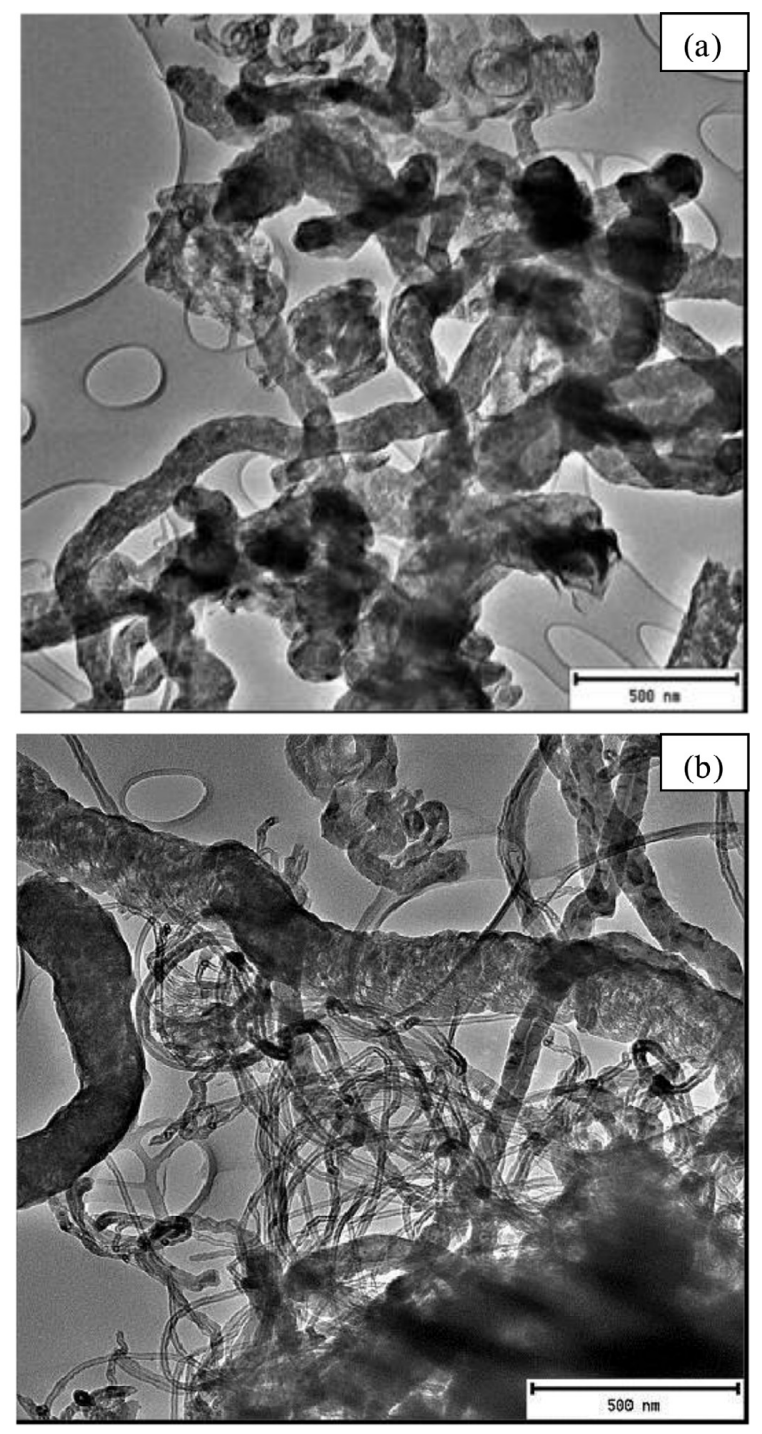

Figure 6 TEM image of the purified carbonaceous materials generated using dichloroethane as chlorine source.

secondary fibre growth was observed. This might also be attributed to the amount of chlorine in the feed, which if present in large amounts inhibits the growth of secondary fibrous particles. The inner diameters of the MWCNTs produced using chlorinated ethanes also increased with an increase in the amount of $\mathrm{Cl}$ contained in the organic reagent (Table 1), which suggests $\mathrm{HCl}$-induced metal agglomeration, as has been demonstrated elsewhere. ${ }^{48,50}$

TEM images of carbon materials produced from TCE and TTCE (Figs. 7a and 8b, respectively) also revealed some morphological differences. The carbon materials showed nanotubes with 'segmented' appearance, i.e. a 'bamboo-like' structure. TEM images have been reported previously in the literature where 'bamboo-like' nanofibres were produced when DCE, dichloroethylene and TCE were used as sources of $\mathrm{Cl}$ over $\mathrm{Ni} / \mathrm{SiO}_{2}$ catalyst and were attributed to a seed metal reconstruction leading to unequal diffusion of carbon through the metal particle. ${ }^{49}$ In our case the bamboo structures might arise from effects related to the interaction of chlorine with metal particles leading to catalyst restructuring. Bamboo structures were not seen for the CNTs obtained in this study when DCE was used which might be due to their limited production but the segmentation was observed from CNFs produced from DCE (Supplementary Fig. S2). More segmented CNTs were observed for
CNTs produced from TCE (Fig. 7a). The distances between compartments appeared similar for both reactants.

\subsection{TGA and PXRD Analysis}

TGA and derivative TGA (DTGA) curves of the purified (Fig. 9) and un-purified (Supplementary Fig. S3) MWCNTs samples were recorded in an oxygen atmosphere to monitor the weight loss and thermal stability of the samples. CNTs synthesized in the presence of chlorine using $\mathrm{CB}, \mathrm{DCB}$ and TCB as chlorine sources, revealed oxidation peaks at $\sim 612^{\circ} \mathrm{C}, 601^{\circ} \mathrm{C}$ and $589^{\circ} \mathrm{C}$, respectively (Table 2). Previously, Mhlanga et. al..$^{56}$ showed that CNTs synthesized using this catalyst with non-chlorinated reactants oxidized at $\sim 550{ }^{\circ} \mathrm{C}$.

From the thermographs and DTGA data (Table 2) it can be seen that the decomposition temperature of the purified CNTs made from the aromatic carbon feeds decreased with an increase in the amount of chlorine. The DTGA curves of these CNTs also show the appearance of peaks at $\sim 690{ }^{\circ} \mathrm{C}$. These peaks are welldefined when generated from $\mathrm{CB}$, but appeared as shoulder peaks for DCB and TCB. These peaks are assigned to the presence of small amounts of graphitic materials. ${ }^{64,65}$

Further evaluation of the thermographs obtained from chlorinated benzenes, revealed that the CNTs contained residues even after purification in $30 \% \mathrm{HNO}_{3}$ for $30 \mathrm{~min}(\sim 21 \%, 6 \%$ and $10 \%$ for CB, DCB and TCB (Table 2)). An attempt was made to further purify the materials generated from $\mathrm{CB}$ by stirring the product in $30 \% \mathrm{HNO}_{3}$ for $2 \mathrm{~h}$ and $3 \mathrm{~h}$ (Supplementary Fig. S4). The residual mass had not changed ( $18 \%$ and $20 \%$ ) after the $2 \mathrm{~h}$ and $3 \mathrm{~h}$ acid treatments. A further harsher treatment was employed by refluxing the product in acid at $110{ }^{\circ} \mathrm{C}$ for $4 \mathrm{~h}$ which resulted in destruction of the CNTs structure but a residual non-carbon mass of $8 \%$ still remained (Supplementary Fig. S4). This showed that catalyst particles remained intact and could not be removed from the CNTs despite the harsh acid treatment used. The results correlated with the TEM observations; where images showed the presence of many catalyst particles embedded inside the CNTs (Fig. 2) as well as at the tip of a few CNFs made from materials produced using DCB (insert in Fig. 3a). This implied that the catalyst particles were embedded (i) inside bamboo structures, (ii) within the graphitic layers of the CNTs and (iii) inside the tips of some CNFs (insert in Fig. 3). Similar results were observed in the literature using a FeNi catalyst when residual metal contents of 31, 27 and $24 \mathrm{wt}$.\% were observed from TGA curves generated from trichlorobenzene, dichlorobenzene and chlorobenzene as carbon sources; a 3 wt. \% residue was observed under the same conditions using xylene as carbon precursor. ${ }^{51}$

Table 2 Decomposition temperatures and residual masses (determined by TGA) of the un-purified and purified (P) chlorinated CNMs.

\begin{tabular}{lcc}
\hline Chlorine source & $\begin{array}{c}\text { DecompositionC } \\
\text { temperature }{ }^{\circ}\end{array}$ & Residual mass/\% \\
\hline CB & 617 & 26.7 \\
CB(P) & 612 & 21.6 \\
DCB & 597 & 29.6 \\
DCB $(P)$ & 601 & 6.6 \\
TCB & 600 & 29.8 \\
TCB $(P)$ & 589 & 10.1 \\
DCE & 550 & 15.9 \\
DCE $(P)$ & 619 & 0.0 \\
TCE & 594 & 13.6 \\
TCE $(P)$ & 621 & 2.5 \\
TTCE & 615 & 13.5 \\
TTCE $(P)$ & 619 & 0.0 \\
\hline
\end{tabular}


S. Afr. J. Chem., 2016, 69, 15-26,

$<$ http://journals.sabinet.co.za/sajchem/>.
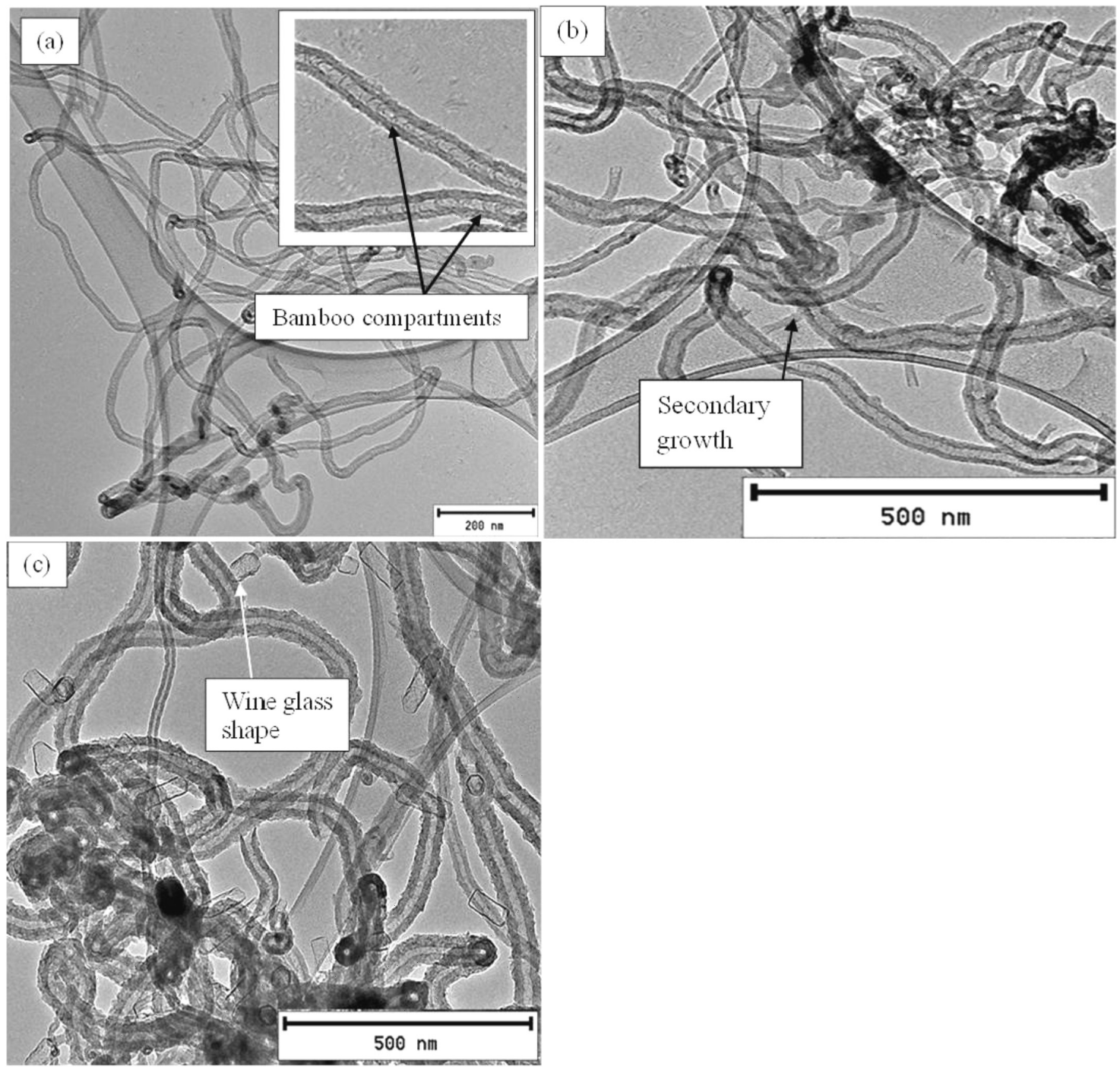

Figure 7 TEM images of the purified carbonaceous materials generated using (a) trichloroethane. Growth of small carbon materials of different shapes on the surface of the CNTs can be seen in (b) and (c).
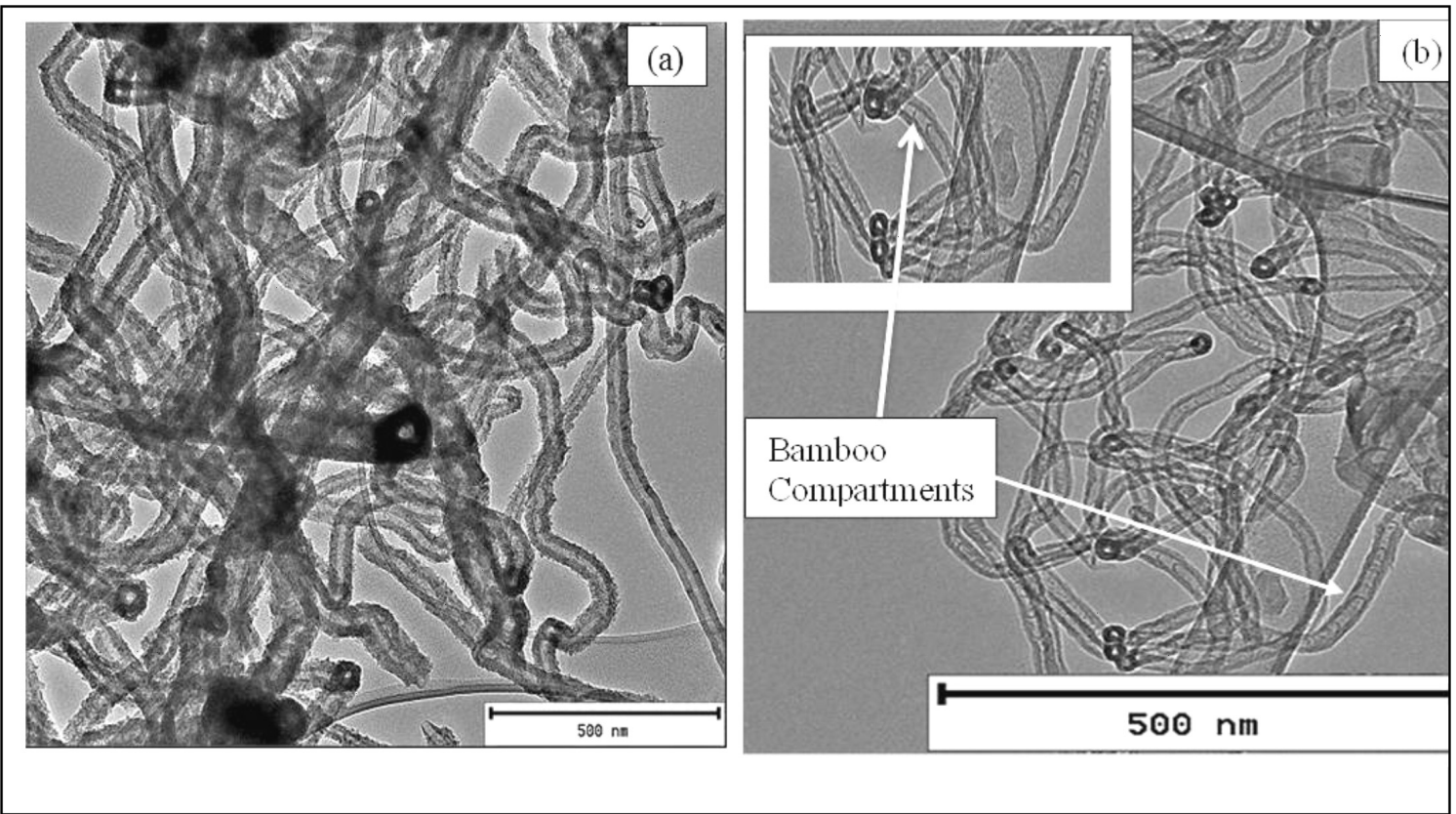

Figure 8 TEM images of the purified carbonaceous materials generated using (a) tetrachloroethane. Bamboo compartments can be seen in (b). 

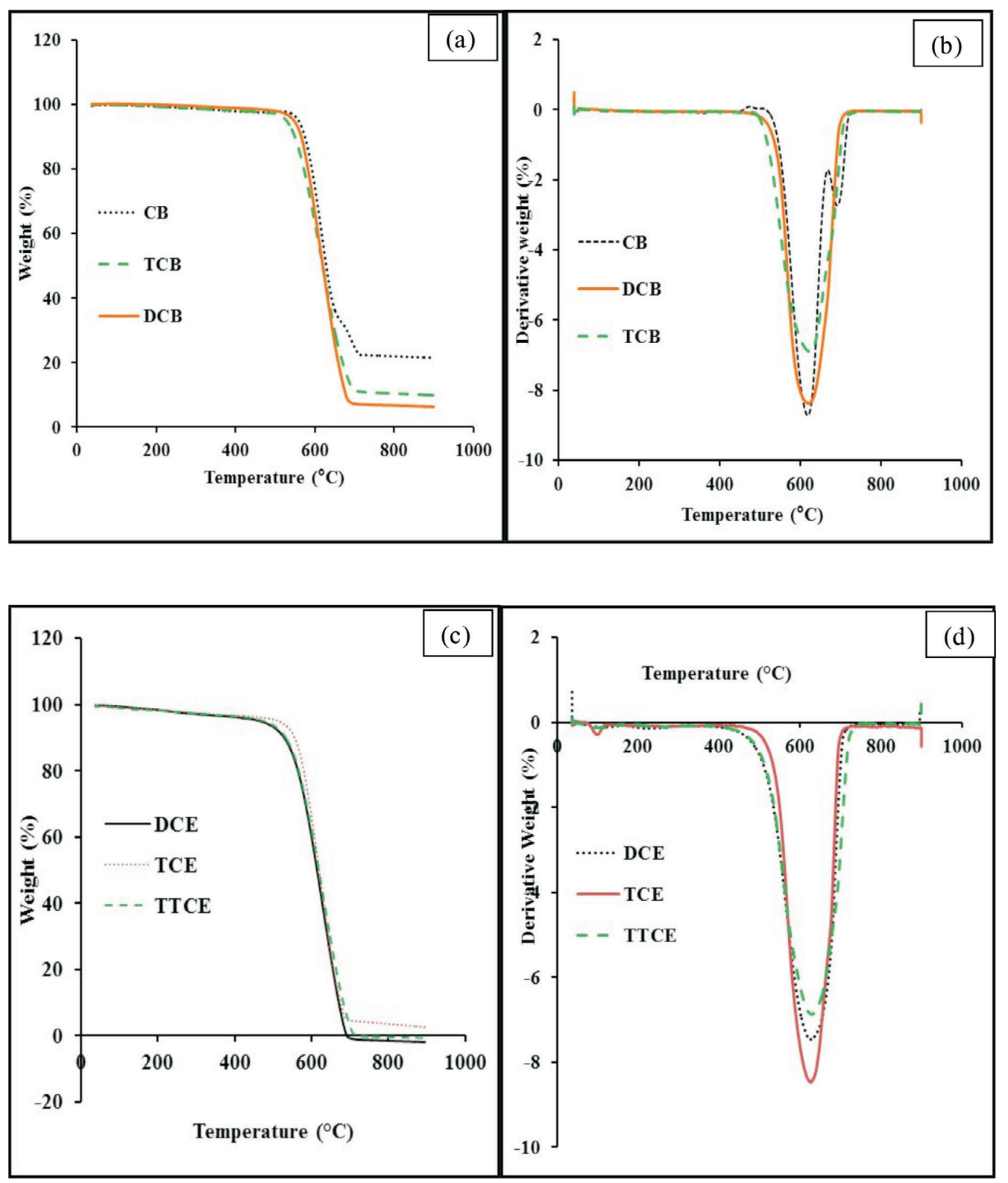

Figure 9 TGA and corresponding derivative profiles of the purified MWCNT samples produced using chlorinated benzenes (a and $\mathbf{b})$ and ethanes (c and $\mathbf{d})$ as $\mathrm{Cl}$ sources.

TGA (Fig. 9c) and DTGA (Fig. 9d) curves generated from chlorinated ethanes all show similar oxidation peaks at $\sim 619{ }^{\circ} \mathrm{C}$ (for DCE and TTCE) and $\sim 621^{\circ} \mathrm{C}$ for TCE. The chlorinated materials are more thermally stable than those produced from chlorinated benzenes. Catalyst particles were not embedded inside the CNTs $(<2 \%)$ for the CNTs produced from the chlorinated ethanes.

XRD characterization was performed, to further analyze the purity of the CNTs. The XRD profiles of the acid-treated (purified) MWCNTs generated from chlorinated hydrocarbons are presented in Fig. 10. All XRD patterns show the presence of graphitic carbon represented by a $\mathrm{C}_{(002)}$ peak at $2 \theta=30^{\circ}$ and another peak at $2 \theta=53^{\circ}$. The peak at $2 \theta=30^{\circ}$ has been attributed to MWCNTs. ${ }^{66}$ The $\mathrm{C}_{(002)}$ peak for CNTs synthesized without chlorine was broader when compared to $\mathrm{C}_{(002)}$ peaks of CNTs synthesized in the presence of chlorine. The full width at half maximum (FWHM) of the $\mathrm{C}_{(002)}$ peak decreased after introduction of chlorine, and increased with an increase in the amount of chlorine in the feed (Table 3). The smaller broadening of the FWHM of the $\mathrm{C}_{(002)}$ peak with an increase in the amount of chlorine was attributed to an increased crystallinity of the materials. .6,67 $^{6}$

For chlorinated ethanes, the FWHM of the $\mathrm{C}_{(002)}$ peak decreased in the order DCE $=$ TTCE $>$ TCE (Table 3). CNTs synthesized using TCE were more crystalline than those generated from DCE and TTCE. These observations agree well with the TGA graphs where CNTs generated from TCE were oxidized at higher temperatures, meaning they were more thermally

Table 3 PXRD structural parameters of purified CNTs synthesized in the absence and presence of chlorine.

\begin{tabular}{cc}
\hline Chlorine source & FWHM of $\mathrm{C}_{(002)}$ peak $/{ }^{\circ}$ \\
\hline None & 3.2 \\
CB & 1.2 \\
DCB & 2.5 \\
TCB & 2.8 \\
DCE & 3.2 \\
TCE & 2.2 \\
TTCE & 3.2 \\
\hline
\end{tabular}




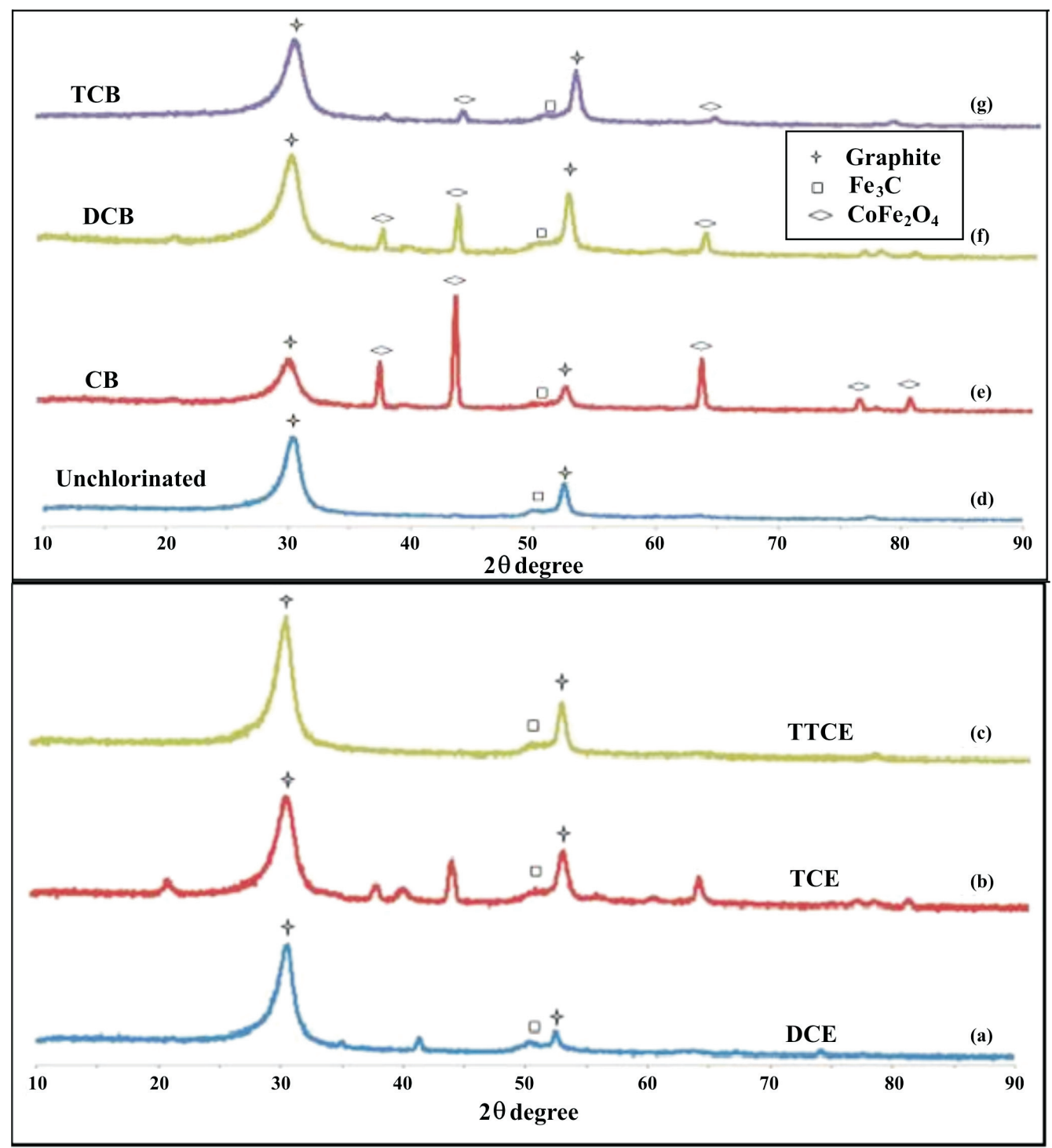

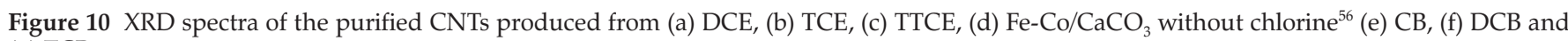
(g) TCB.

stable than those generated from other chlorinated ethane feeds.

Another broad peak closer to the one at $53^{\circ}$ was attributed to small amounts of carbides in the carbon material. PXRD analysis revealed peaks at $2 \theta \sim 38^{\circ}, 43^{\circ}$ and $64^{\circ}$ due to the presence of cobalt ferrite nanoparticles ${ }^{68}$ for CNTs generated from CB, DCB, TCB and TCE, confirming that some metal particles still remained after purification as confirmed by the TGA analysis. Other diffraction peaks can be seen in the XRD patterns generated from TCE after purification which can be due to the presence of catalyst residues remaining after purification.

\subsection{Raman Spectral Analysis}

The crystalline nature of the MWCNT structures was verified by Raman spectroscopy. Raman spectra for all chlorinated MWCNTs (Figs. 11 and 12) shows a D-band at around $1350 \mathrm{~cm}^{-1}$ which is attributed to defects in the curved graphene layers and tube ends and a G-band at around $1576 \mathrm{~cm}^{-1}$ which correspond to the movement in the opposite direction of two neighbouring carbon atoms in a graphene sheet. The intensity ratio $\mathrm{I}_{\mathrm{D}} / \mathrm{I}_{\mathrm{G}}$ is known to depend on the structural characteristics of the CNTs. ${ }^{69}$ An increase in $\mathrm{I}_{\mathrm{D}} / \mathrm{I}_{\mathrm{G}}$ corresponds to a higher proportion of $\mathrm{sp}^{3}$ carbon that is usually attributed to the presence of more structural defects. ${ }^{70} \mathrm{I}_{\mathrm{D}} / \mathrm{I}_{\mathrm{G}}$ ratios of $0.96,0.96$ and 0.76 were observed for
CNTs produced from CB, DCB and TCE, respectively (Table 4). These ratios increased slightly as compared to those shown by Mhlanga et.al..$^{56}$ for unchlorinated CNTs (0.7). This shows that the CNTs remained graphitic after addition of chlorine, which agrees with the TGA and XRD data. The $\mathrm{I}_{\mathrm{D}} / \mathrm{I}_{\mathrm{G}}$ peak ratio of the CNTs generated from TCB is also comparable $(\sim 0.76)$ with the ratio obtained for CNTs produced without chlorine $\left(\sim 0.7^{56}\right)$.

The $\mathrm{I}_{\mathrm{D}} / \mathrm{I}_{\mathrm{G}}$ peak ratio for CNTs produced from DCE $(0.89)$ and TTCE (0.89) were similar, and agreed well with the TGA and the XRD data. Structural defects, shown by the highly intense D

Table 4 D-bands, G-bands, 2D-bands and $\mathrm{I}_{\mathrm{D}} / \mathrm{I}_{\mathrm{G}}$ ratios of the purified chlorinated CNMs.

\begin{tabular}{lcccc}
\hline Chlorine source & $\begin{array}{c}\text { D-band } \\
/ \mathrm{cm}^{-1}\end{array}$ & $\begin{array}{c}\text { G-band } \\
/ \mathrm{cm}^{-1}\end{array}$ & $\begin{array}{c}2 \mathrm{D} \text {-band } \\
/ \mathrm{cm}^{-1}\end{array}$ & $\mathrm{I}_{\mathrm{D}} / \mathrm{I}_{\mathrm{G}}$ ratio \\
\hline CB & 1338 & 1576 & 2681 & 0.96 \\
DCB & 1338 & 1589 & - & 0.96 \\
TCB & 1341 & 1576 & 2680 & 0.76 \\
Toluene & 1338 & 1574 & 2678 & 0.71 \\
DCE & 1339 & 1575 & 2679 & 0.89 \\
TCE & 1341 & 1581 & - & 1.19 \\
TTCE & 1338 & 1574 & 2678 & 0.89 \\
\hline
\end{tabular}

- No peak observed or the observed peak height is negligible. 


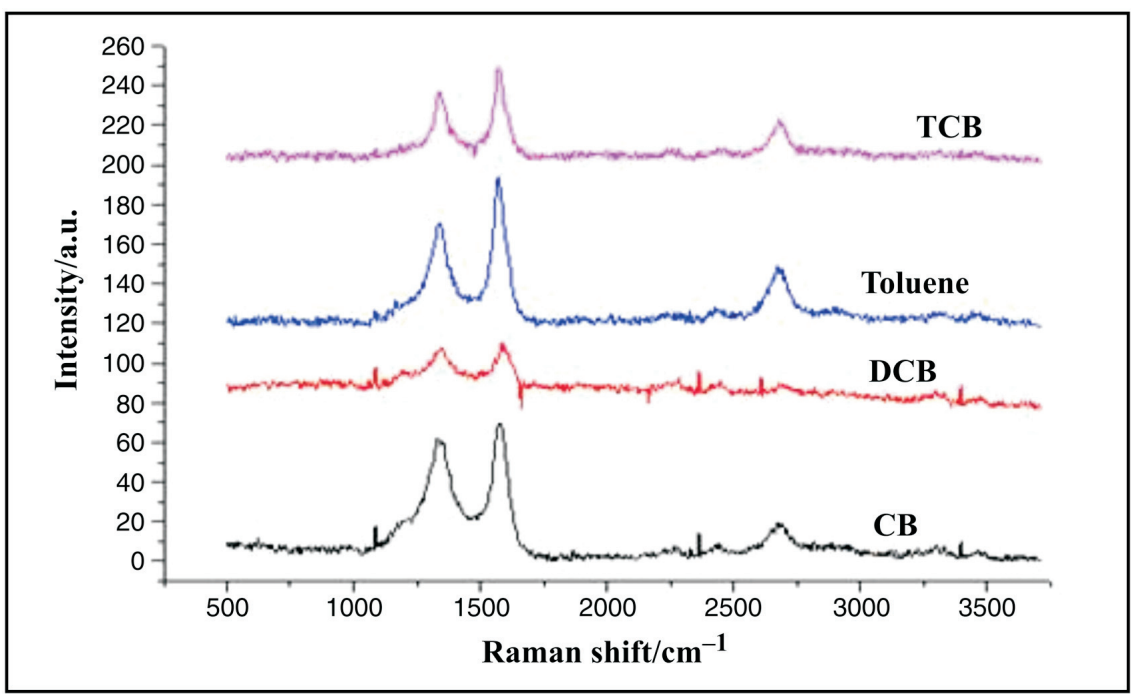

Figure 11 Raman spectra of the purified CNTs produced from $\mathrm{CB}, \mathrm{DCB}, \mathrm{TCB}$ and toluene.

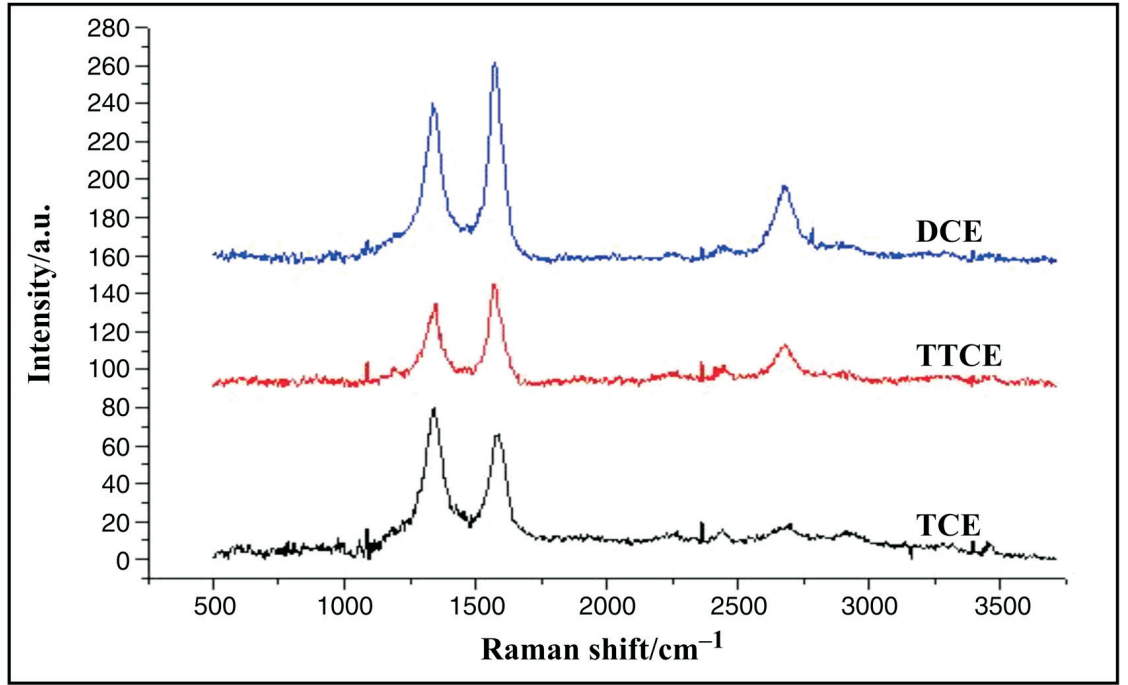

Figure 12 Raman spectra of the purified CNTs produced from DCE, TCE and TTCE.

peak (Fig. 12), were obtained when TCE was used as a source of chlorine. These can be associated with the formation of bamboo-like CNTs and the growth of open-ended carbon nanostructures onto the main CNTs as observed from TEM images. An overtone $2 \mathrm{D}$ peak was also observed at $\sim 2680 \mathrm{~cm}^{-1}$ in the spectra of CNTs generated from DCE, TTCE, CB, TCB and toluene (Figs. 11 and 12). This suggests that the materials have a good percentage of graphitic carbon, which agrees with the lower $\mathrm{I}_{\mathrm{D}} / \mathrm{I}_{\mathrm{G}}$ ratios produced for these materials.

\subsection{Energy Dispersive X-ray Spectroscopy Analysis of the Purified Chlorinated CNMs}

The EDS analysis (Table 5) revealed the presence of $\mathrm{Cl}$ species in all chlorinated samples. It was found that the amount of $\mathrm{Cl}$ on the MWCNTs (i) increased with an increase in the amount of $\mathrm{Cl}$ in the organic reagents and (ii) aromatic reactants gave less $\mathrm{Cl}$ substitution than aliphatic reactants (Table 5). This demonstrates that the use of highly chlorine substituted feeds, gives greater functionalization of CNTs with $\mathrm{Cl}$. The data correlate with the TEM data where TCE and TTCE gave more segmented CNTs; hence incorporation of $\mathrm{Cl}$ into the carbon structure and secondary fibrous growth observed on the surface of the CNTs can be related to the amount of $\mathrm{Cl}$ present.

\subsection{XPS Analysis}

The surface characteristics of purified MWCNTs were analyzed by XPS. Supplementary Figs. S5 and S6 shows the deconvoluted XPS plots of $\mathrm{C} 1 \mathrm{~s}$ and $\mathrm{Cl} 2 \mathrm{p}$ for all the studied chlorinated organics. The C1s curve for all MWCNTs was deconvoluted into five components with binding energies of $\sim 284.0,284.8,285.4$, 286.1 and $286.8 \mathrm{eV}$ (Table 6). Four of these peaks are readily assigned to $\mathrm{C} \mathrm{sp}^{2}, \mathrm{C} \mathrm{sp}{ }^{3}, \mathrm{C}-\mathrm{OH}$ and $\mathrm{C}=\mathrm{O}$; it is possible to tentatively assign the fifth peak at 285.4 to $\mathrm{C}$ covalently attached to $\mathrm{Cl}^{72,73}$

The $\mathrm{Cl} 2 \mathrm{p}$ spectrum of CNTs generated from chlorinated organics (Supplementary Figs. S5 and S6) showed two signals at $\sim 201$ and $199 \mathrm{eV}$ which are assigned to the $2 \mathrm{p}_{1 / 2}$ and $2 \mathrm{p}_{3 / 2}$ of a chloride ion (e.g. as found in metal chlorides) ${ }^{73,74}$ Unfortunately the $2 p_{1 / 2}$ peak associated with covalent $\mathrm{C}-\mathrm{Cl}$ bonds overlaps with the $2 p_{3 / 2}$ associated with the presence of the chloride ion peak. Furthermore, the low concentration of the $\mathrm{Cl}$ in the samples generates very small peaks for $\mathrm{Cl}$ and this makes it difficult to quantify the amount of covalent $\mathrm{Cl}$ in the CNTs. However the $2 p_{1 / 2} / 2 p_{3 / 2}$ ratios for the $\mathrm{Cl}$ peaks indicate values below $c a$. 1.6, the value expected when only ionic chloride is present (Supplementary Table S1). This suggests that indeed small amounts of C-Cl bonds have been made; the CNTs made from TTCE thus have 
Table 5 EDS analysis of chlorinated-CNMs grown using different chlorinated organic solvents.

\begin{tabular}{cc}
\hline Chlorine source & $\begin{array}{c}\text { Chlorine }(\mathrm{Cl}) \text { weight } \\
/ \%\end{array}$ \\
\hline CB & 0.07 \\
DCB & 0.12 \\
TCB & 0.26 \\
DCE & 0.27 \\
TCE & 0.75 \\
TTCE & 1.53 \\
\hline
\end{tabular}

Table 6 XPS analysis of purified chlorine functionalized CNTs grown using different chlorine sources.

\begin{tabular}{|c|c|c|}
\hline \multirow[b]{2}{*}{ Chlorine source } & \multicolumn{2}{|c|}{$\begin{array}{l}\text { Binding energy/eV (and } \\
\text { atomic concentration/\%) }\end{array}$} \\
\hline & $\mathrm{C}$ & $\mathrm{Cl}$ \\
\hline $\mathrm{CB}$ & $\begin{array}{l}284.0(69.7 \%) \\
284.8(14.7 \%) \\
285.3(7.44 \%) \\
286.0(4.20 \%) \\
287.0(3.95 \%)\end{array}$ & $\begin{array}{l}199.4(58.1 \%) \\
201.0(41.9 \%)\end{array}$ \\
\hline DCB & $\begin{array}{l}284.0(65.5 \%) \\
284.8(16.5 \%) \\
285.4(13.2 \%) \\
286.2(1.43 \%) \\
287.0(3.50 \%)\end{array}$ & $\begin{array}{l}199.0(59.8 \%) \\
200.1(40.2 \%)\end{array}$ \\
\hline TCB & $\begin{array}{l}284.0(72.1 \%) \\
284.9(13.9 \%) \\
285.5(6.51 \%) \\
286.0(2.0 \%) \\
287.0(5.52 \%)\end{array}$ & $\begin{array}{l}199.2(62.9 \%) \\
200.8(37.1 \%)\end{array}$ \\
\hline DCE & $\begin{array}{l}283.9(62.3 \%) \\
284.5(16.5 \%) \\
285.1(12.7 \%) \\
285.7(4.88 \%) \\
286.7(3.64 \%)\end{array}$ & $\begin{array}{l}199.0(63.8 \%) \\
200.6(36.2 \%)\end{array}$ \\
\hline TCE & $\begin{array}{l}284.0(69.1 \%) \\
284.7(8.82 \%) \\
285.2(13.9 \%) \\
286.0(5.72 \%) \\
286.7(2.42 \%)\end{array}$ & $\begin{array}{l}199.0(59.1 \%) \\
200.9(40.8 \%)\end{array}$ \\
\hline TTCE & $\begin{array}{l}284.0(62.9 \%) \\
284.7(22.1 \%) \\
285.2(10.7 \%) \\
285.8(3.52 \%) \\
286.6(0.685 \%)\end{array}$ & $\begin{array}{l}199.3(54.5 \%) \\
200.9(45.6 \%)\end{array}$ \\
\hline
\end{tabular}

the largest amount of $\mathrm{C}-\mathrm{Cl}$ bonds. This chlorine would be attached to $\mathrm{sp}^{2}$ carbons at the periphery of the aromatic structures, or at defect sites. ${ }^{72}$ The low $\mathrm{Cl}$ content is not unexpected as $\mathrm{C}-\mathrm{Cl}$ bonds are readily broken under the high temperature condition employed in the CNT synthesis.

\section{Conclusion}

The role of chlorine on the morphology of MWCNTs synthesized by the catalytic pyrolysis of chlorinated organic reagents over a Fe-Co/ $\mathrm{CaCO}_{3}$ catalyst was studied. The structural morphology of CNTs produced depended on the amount of chlorine present in the feed and on the type of organic chlorine compound used. CNTs generated from TCE and TTCE showed the formation of bamboo-like structures, which were related to catalyst restructuring by chlorine. Secondary nanofibre and nanotube growth onto the main CNTs was observed when TCE and DCB chlorine sources were used. Carbon nanofibres were found to be dominant when chlorine sources that contained high concentration of hydrogen were used. Addition of chlorine favoured the growth of carbon materials of high purity. Alkanes gave cleaner CNTs with higher carbon yields than those formed from the aromatic reactants. XPS studies revealed that most of the $\mathrm{Cl}$ found in the CNTs was ionic chlorine, most probably associated with the Fe and in the CNT tubes. Some surface functionalization of carbon with chlorine is suggested when TTCE was used as reagent. The role of chlorine on the morphology of nitrogen-doped CNTs and the use of chlorinated MWCNTs as adsorbents for selected heavy metals in wastewater treatment is under way.

\section{Acknowledgements}

The authors would like to acknowledge financial support from Vaal University of Technology and the University of the Witwatersrand. We also thank the MMU unit at University of the Witwatersrand for use of the microscopes.

\section{References}

1 H.W. Kroto, J.R. Heath, S.C. O'Brien, R.F. Curl and R.E. Smalley, C60: Buckminsterfullerene, Nature, 1985, 318, 162-163.

2 S. Ijima, Helical Microtubules of graphitic carbon, Nature, 1991, 354, 56-66.

3 P.G. Collins and P. Avouris, Nanotubes for electronics, Scientific American, 2000, 283, 62-69.

4 Q. Zeng, Z. Li and Y. Zhou, Synthesis and application of carbon nanotubes, J. Nat. Gas Chem., 2006, 15, 235-246.

5 B.M. Endo, T. Hayashi, Y.A. Kim and M. Terrones, M.S. Dresselhaus, Applications of carbon nanotubes in the twenty-first century, Phil. Trans. Roy. Soc. London. A., 2004, 362, 2223-2238.

6 M. Terrones, A. Jorio, M. Endo, Y.A. Kim, T. Hayashi, H. Terrones, J.-C. Charlier, G. Dresselhaus and M.S. Dresselhaus, New direction in nanotube science, Mater. Today, 2004, 7, 30-45.

7 H. Zeng, L. Zhu, G. Hao and R. Sheng, Synthesis of various forms of carbon nanotubes by AC arc discharge, Carbon, 1998, 36, 259-262.

8 A. Thess, R. Lee, P. Nikolaev, H. Dai, P. Petit, J. Robert, C. Xu, Y.H. Lee, S.G. Kim, A.G. Rinzler, D.T. Colbert, G.E. Scuseria, D. Tombnek and J.E. Fischer, Crystalline ropes of metallic carbon nanotubes, Science, 1996, 273, 483-487.

9 D.C. Li, L. Dai, S. Huang, A.W.H. Mau and Z.L. Wang, Structure and growth of aligned carbon nanotube films by pyrolysis, Chem. Phys. Lett., 2000, 316, 349-355.

10 V. Ivanov, J.B. Nagy, P. Lambin, A. Lucas, X.B. Zhang, X.F. Zhang, D. Bernaerts, G. Van Tendeloo, S. Amelinckx and J. Van Landuyt, The study of carbon nanotubules produced by catalytic method, Chem. Phys. Lett., 1994, 223, 329-335.

11 S.Y. Brichka, G.P. Prikhod'ko, Y.I. Sementsov, A.V. Brichka, G.I. Dovbeshko and O.P. Paschuk, Synthesis of carbon nanotubes from a chlorine-containing precursor and their properties, Carbon, 2004, 42, 2581-2587.

12 K. Chizari, A. Vena, L. Laurentius and U. Sundararaj, The effect of temperature on the morphology and chemical surface properties of nitrogen-doped carbon nanotubes, Carbon, 2014, 68, 369-379.

13 C. Wang, Z. Huang, L. Zhan, Y. Wang, W. Qiao, X. Liang and L. Ling, Nitrogen-doped carbon nanotubes synthesized with carbon nanotubes as catalyst, Diam. Rel. Mat., 2011, 20, 1353-1356.

14 T. Sharifi, F. Nitze, H.R. Barzegar, C.-W. Tai, M. Mazurkiewicz, A. Malolepszy, L. Stobinski and T. Wågberg, Nitrogen-doped multiwalled carbon nanotubes produced by CVD-correlating XPS and Raman spectroscopy for the study of nitrogen inclusion, Carbon, 2012, 50, 3535-3541.

15 G. Bepete, Z.N. Tetana, S. Lindner, M.H. Rummeli, Z. Chiguvare and N.J. Coville, The use of aliphatic alcohol chain length to control the nitrogen type and content in nitrogen doped carbon nanotubes, Carbon, 2013, 52, 316-325.

16 H. Liu, Y. Zhang, R. Li, X. Sun and H. Abou-Rachid, Thermal and 
chemical durability of nitrogen-doped carbon nanotubes, J. Nanopart. Res., 2012, 14, 1016-1023.

17 L. Faba, Y.A. Criado, E. Gallegos-Suáres, M. Pérez-cadenas, E. Díaz, I. Rodríquez-Ramos, A. Guerrero-Ruiz and S. Ordónez, Preparation of nitrogen-containing carbon nanotubes and study of their performance as basic catalysts, Appl. Catal. A: Gen., 2013, 458, 155-161.

18 R. Czerw, M. Terrones, J.-C. Charlier, X. Blasé, B. Foley, R. Kamalakaran, N. Grobert, H. Terrones, D. Tekleab, P.M. Ajayan, W. Blau, M. Rühle and D.L. Carroll, Identification of electron donor states in N-doped carbon nanotubes, Nano. Lett., 2001, 9, 457-560.

19 S. Maldonado, S. Morin and K. Stevenson, Structure, composition and chemical reactivity of carbon nanotubes by selective nitrogen doping, Carbon, 2006, 44, 1429-1437.

20 P.L. Gai, O. Stephan, K. McGuire, A.M. Rao, M.S. Dresselhaus, G. Dresselhaus and C. Colliex, Structural systematics in boron-doped single wall carbon nanotubes, J. Mater. Chem., 2004, 14, 669-675.

21 R. Czerw, P.-W. Chiu, Y.-M. Choi, D.-S. Lee, D.L. Carroll, S. Roth and Y.-W. Park, Substitutional boron-doping of carbon nanotubes, Curr. Appl. Phys., 2002, 2, 473-477.

22 H.J. Ceragioli, A.C. Peterlevitz, J.C.R. Quispe, A. Larena, M.P. Pasquetto, M.A. Sampaio and V. Baranauskas, Synthesis and characterization of boron-doped carbon nanotubes, J. Phys.: Conf. Ser., 2008, 100, 052029, DOI: 10.1088/1742-6596/100/5/052029.

23 K. McGuire, N. Gothard, P.L. Gai, M.S. Dresselhaus, G. Sumanasekera and A.M. Rao, Synthesis and Raman characterisation of boron-doped single-walled carbon nanotubes, Carbon, 2005, 43, 219-227.

24 F.H. Monteiro, D.G. Larrude, M.E.H. Maia da Costa, L.A. Terrazos, R.B. Capaz and F.L. Freire Jr., Production and characterization of boron-doped single wall carbon nanotubes, J. Phys. Chem. C, 2012, 116, 3281-3285.

25 T. Cui, R. Lv, Z.H. Huang, F. Kang, K. Wang and D. Wu, Effect of sulphur on enhancing nitrogen-doping and magnetic properties of carbon nanotubes, Nanoscale. Res. Lett., 2011, 6, 77-82.

26 F. Bottger-Hiller, A. Mehner, S. Anders, L. Kroll, G. Cox, F. Simon and S. Spange, Sulphur-doped porous carbon rom a thiophene-based twin monomer, Chem. Comm., 2012, 48, 10568-10570.

27 C. Shan, W. Zhao, X.L. Lu, D.J. O'Brien, Y. Li, Z. Cao, A.L. Elias, R. Cruz-Silva, M. Terrone, B. Wei, and J. Suhr, Three-dimensional nitrogen-doped multiwall carbon nanotube sponges with tunable properties, Nano. Lett., 2013, 13, 5514-5520.

28 Q. Shi, F. Peng, S. Liao, H. Wang, H. Yu, Z. Liu, B. Zhang and D. Su, Sulphur and nitrogen co-doped carbon nanotubes for enhancing electrochemical oxygen reduction activity in acidic and alkaline media, J. Mater. Chem. A., 2013, 1, 14853-14857.

29 J. Li, L. Wang, Y.J. Su, P. Liu and Y.F. Zhang, Semiconducting singlewalled carbon nanotubes synthesized by S-doping, Nano-Micro Lett., 2009, 1, 9-13.

30 X. Qu, P.J.J. Alvarez and Q. Li, Photochemical transformation of carboxylated multiwalled carbon nanotubes: role of reactive oxygen species, Environ. Sci. Technol., 2013, 47, 14080-14088.

31 B. Zhong, H. Liu, X. Gu and D.S. Su, Study of the role of surface oxygen functional groups on carbon nanotubes in the selective oxidation of acrolein, Chem. Cat. Chem., 2014, 6, 1553-1557.

32 D. Srivastava, T. Susi, M. Borghei and L. Kari, Dissociation of oxygen on pristine and nitrogen-doped carbon nanotubes: aspin polarized density functional study, RSC Adv., 2014, 4, 15225-15235.

33 G.D. Nessim, A. Al-Obeidi, H. Grisaru, E.S. Polsen, C.R. Oliver, T. Zimrin, A.J. Hart, D. Aurbach and C.V. Thompson, Synthesis of tall carpets of vertically aligned carbon nanotubes by in situ generation of water vapour through preheating of added oxygen, Carbon, 2012, 50, 4002-4009.

34 P.C.P. Watts, N. Mureau, Z. Tang, Y. Miyajima, J.D. Carey and S.R.P. Silva, The importance of oxygen-containing defects on carbon nanotubes for the detection of polar and non-polar vapours through hydrogen bond formation, Nanotechnol., 2007, 18, 175701, DOI: 10.1088/0957-4484/18/17/175701.

35 J. Zhao and R.-H. Xie, Electronic and photonic properties of doped carbon nanotubes, J. Nanosci. Nanotechnol., 2003, 3, 459-478.

36 S. Niyogi, M.A. Hamon, H. Hu, B. Zhao, P. Bhowmik, R. Sen, M.E. Itkis and R.C. Haddon, Chemistry of single-walled carbon nanotubes, Acc. Chem. Res., 2002, 35, 1105-1113.
37 S.M. Kim, K.K. Kim, Y.W. Yo, M.H. Park, S.J. Chae, D.L. Duong, C.W. Yang, J. Kong and Y.H. Lee, Role of anions in the $\mathrm{AuCl}_{3}$-doping of carbon nanotubes, ACS Nano., 2011, 5, 1236-1242.

38 J.K. Wassei, K.C. Cha, V.C. Tung, Y. Yang and R.B. Kaner, The effects of thionyl chloride on the properties of graphene and graphene-carbon nanotube composites, J. Mater. Chem., 2011, 21, 3391-3396.

39 D.L. Duong, I.H. Lee, K.K. Kim, J. Kong, S.M. Lee and Y.H. Lee, Carbon nanotube doping mechanism in a salt solution and hygroscopic effect: density functional theory, ACS Nano., 2010, 4, 5430-5436.

40 J.-M. Yuan, X.-H. Chen, X.-H Chen, Z.-F. Fan, X.-G. Yang and Z.-H.Chen, An easy method of purifying multi-walled carbon nanotubes by chlorine oxidation, Carbon, 2008, 46, 1266-1269.

41 W.H. Lee, S.J. Kim, W.J. Lee, J.G. Lee, R.C. Haddon and P.J. Reucroft, X-ray photoelectron spectroscopic studies of surface modified singlewalled carbon nanotubes material, Appl. Surf. Sci., 2001,181, 121-127.

42 Z. Kónya, I. Vesselenyi, K. Niesz, A. Kukovecz, A. Demortier, A. Fonseca, J. Delhalle, Z. Mekhalif, J.B. Nagy, A.A. Koós, Z. Osváth, A. Kocsonya, L.P. Biró and I. Kiricsi, Large scale production of short functionalized carbon nanotubes, Chem. Phys. Lett., 2002, 360, $429-435$.

43 I. Pełech, U. Narkiewicz, D. Moszyñski and R. Pelech, Simultaneous purification and functionalization of carbon nanotubes using chlorination, J. Mater. Res., 2012, 27, 2368-2374.

44 C. Ghemes, A. Ghemes, M. Okada, H. Mimura, T. Nakano and Y. Inoue, Study of growth enhancement of multiwalled carbon nanotubes by chlorine-assisted chemical vapour deposition, Japanese J. Appl. Phys., 2013, 52 , 035202.

45 J. Barkauskas, I. Stankevièiene and A. Selskis, A novel purification method of carbon nanotubes by high temperature treatment with tetrachloromethane, Sep. Pur. Tech., 2010, 71, 331-336.

46 J.L. Zimmerman, R.K. Bradley, C.B. Huffman, R.H. Hauge and J.L. Margrave, Gas-phase purification of single-wall carbon nanotubes, Chem. Mater., 2000, 12, 1361-1366.

47 H. Qiu, Z. Shi, L. Guan, L. You, M. Gao, S. Zhang, J. Qiu and Z. Gu, High-efficient synthesis of double-walled carbon nanotubes by arc discharge method using chloride as a promoter, Carbon, 2006, 44, 516-521.

48 L.D. Cherukuri, G. Yuan and M.A. Keane, Catalytic growth of structured carbon via the decomposition of chlorobenzene over $\mathrm{Ni} / \mathrm{SiO}_{2}$ Top. Catal., 2004, 29, 119-128.

49 A.N. Márquez, J.L. Valverde and M.A. Keane, Catalytic growth of structured carbon from chloro-hydrocarbons, Appl. Catal. A: Gen., 2007, 332, 237-246.

50 M.A. Keane, G. Jacobs and P.M. Patterson, $\mathrm{Ni} / \mathrm{SiO}_{2}$ Promoted growth of carbon nanofibers from chlorobenzene: characterization of the active metal sites, J. Colloid Interface Sci., 2006, 302, 576-588.

51 R. Lv, F. Kang, W. Wang, J. Wei, J. Gu, K. Wang and D. Wu, Effect of using chlorine-containing presursors in the synthesis of FeNi-filled carbon nanotubes, Carbon, 2007, 45, 1433-1438.

52 X. Gui, K. Wang, J. Wei, X. Zhang, R. Lv, Y. Jia, Q. Shu, F. Kang and D. $\mathrm{Wu}$, The decisive roles of chlorine-contained precursor and hydrogen for the filling of Fe nanowires into carbon nanotubes, Mater. Chem. Phys., 2009, 113, 634-637.

53 M. Kao, Chemical Vapour Deposition Synthesis of Carbons From Halogen and Silicon Sources, M.Sc. dissertation, University of the Witwatersrand, Johannesburg, South Africa, 2010.

54 A. Shaikjee and N.J. Coville, Catalyst restructuring studies: the facile synthesis of tripod-like carbon fibres by the decomposition of trichloroethylene, Mater. Lett., 2012, 68, 273-276.

55 W.-H. Lin, T.-T. Lee and Y.-Y. Li, Chlorine effect on formation of turbostratic carbon nanofibers by a mixture of 1,2-dichloroethane and ethanol, J. Taiwan Inst. Chem. Eng. E, 2014, 45, 1883-1891.

56 S.D. Mhlanga, K.C. Mondal, R. Carter, M.J. Witcomb and N.J. Coville, The effect of synthesis parameters on the catalytic synthesis of multiwalled carbon nanotubes using $\mathrm{Fe}-\mathrm{Co} / \mathrm{CaCO}_{3}$ catalysts, S. Afr. J. Chem., 2009, 62, 67-76.

57 S.D. Mhlanga and N.J. Coville, Iron-cobalt catalysts synthesized by a reverse micelle impregnation method for controlled growth of carbon nanotubes, Diam. Rel. Mater., 2008, 17, 1489-1497.

58 Z.N. Tetana, S.D. Mhlanga, G. Bepete, R.W.M. Krause and N.J. Coville, The synthesis of nitrogen-doped multiwalled carbon 
nanotubes using an $\mathrm{Fe}-\mathrm{Co} / \mathrm{CaCO}_{3}$ catalyst, S. Afr. J. Chem., 2012, 65, $39-49$.

59 H. Kathyayini, N. Nagaraju, A. Fonseca and J.B. Nagy, Catalytic activity of $\mathrm{Fe}$, $\mathrm{Co}$ and $\mathrm{Fe}-\mathrm{Co}$ supported on $\mathrm{Ca}$ and $\mathrm{Mg}$ oxides, hydroxide and carbonates in the synthesis of carbon nanotubes, J. Mol. Catal. A: Chem., 2004, 223, 129-136.

60 A.A. Hosseini, S. Mehralitabar, A.A. Hosseini, M. Pashaee and F. Taleshi, Proceedings of the 4th International Conference on Nanostructures (ICNS4). 12-14 March, 2012. Kish Island. I.R. Iran. 1296-1298.

61 N. Das, A. Dalai, J.S.S. Mohammadzadeh and J. Adjaye, The effect of feedstock and process conditions on the synthesis of high purityCNTs from aromatic hydrocarbons, Carbon, 2006, 44, 2236-2245.

62 K. Hernadi, A. Fonseca, J.B. Nagya, A. Siska and I. Kiricsi, Production of nanotubes by the catalytic decomposition of different carbon containing compounds, App. Cat. A: Gen., 2000, 199, 245-255.

63 F. Ohashi, G.Y. Chen, V. Stolojan and S.R.P. Silva, The role of the gas species on the formation of carbon nanotubes during thermal chemical vapour deposition, Nanotechnol., 2008, 19, 445605.

64 C.H. See and A.T. Harris, $\mathrm{CaCO}_{3}$ Supported Co-Fe catalysts for carbon nanotube synthesis in fluidized bed reactors, Particle Tech. Fluidization, 2008, 54, 657-664.

65 S. Santangelo, M. Lanza and C. Milone, Evaluation of the overall crystalline quality of amorphous carbon containing multi-walled nanotubes. J. Phys. Chem. C, 2013, 117, 4815-4823.

66 I.D. Rosca, F. Watari, M. Uo and T. Akasaka, Oxidation of multiwalled carbon nanotubes by nitric acid, Carbon, 2002, 43, 3124-3131.
67 L.M. Ombaka, P.G. Ndungu and V.O. Nyamori, Tuning the nitrogen content and surface properties of nitrogen-doped carbon nanotubes synthesized using a nitrogen-containing ferrocenyl derivative and ethylbenzoate, J. Mater. Sci., 2015, 50, 1187-1200.

68 M. Sajjia, M. Oubaha, M. Hasanuzzaman and A.G. Olabi, Developments of cobalt ferrite nanoparticles prepared by the sol-gel process, Ceram. Int., 2014, 40, 1147-1154.

69 L.G. Cancado, A. Jorio, E.H. Martins Ferreira, F. Stavale, C.A. Achete, R.B. Capaz, M.V.O. Moutinho, A. Lombardo, T.S. Kulmala and A.C. Ferrari, Quantifying defects in graphene via Raman spectroscopy at different excitation energies, NanoLetters, 2011, 11, 3190-3196.

70 L. Shao, G. Tobias, C.G. Salzmann, B. Ballesteros, S.Y. Hong, A. Crossley, B.G. Davis and M.L.H. Green, Removal of amorphous carbon for the efficient side wall functionalization of single-walled carbon nanotubes, Chem. Commun., 2007, 5090-5092.

71 J.P. Cheng, X.B. Zhang, F. Liu, J.P. Tu, H.M. Lu, Y.L. Sun and F. Chen, Long bundles of aligned carbon nanofibers obtained by vertical floating catalyst method, Mater. Chem. Phys., 2004, 87, 241-245.

72 E. Papirer, R. Lacroix, J.-B. Donnet, G. Nanse and P. Fioux, XPS Study of the halogenation of carbon black - Part 2. Chlorination, Carbon, 1995, 33, 63-72.

73 X. Zhang, A. Hsu, H. Wang, Y. Song, J. Kong, M.S. Dresselhaus and T. Palacios, Impact of chlorine functionalization on high-mobility chemical vapour deposition grown graphene, ASC Nano, 2013, 7,7262-7270.

74 L. Fan, H. Zhang, P. Zhang and X. Sun, One-step synthesis of chlorinated graphene by plasma enhanced chemical vapour deposition, Appl. Surf. Sci., 2015, 347, 632-635. 